\title{
STIMULASI WIRAUSAHA PADA MURID SEKOLAH MENENGAH ATAS DI TANJUNG PURA LANGKAT SUMATERA UTARA MELALUI WORKSHOP PEMBUATAN LOSION ANTI NYAMUK BERBASIS HERBAL
}

\author{
Yuandani $^{1}$, Marianne ${ }^{2}$, Popi Patilaya ${ }^{3}$ \\ ${ }^{123}$ Fakultas Farmasi Universitas Sumatera Utara \\ Jalan Almamater No.5, Pintu 4, Kampus USU Medan 20155 \\ Email:yuan_dani@yahoo.com
}

\begin{abstract}
Abstrak
SMA N 1 Tanjung Pura dan SMA Swasta Samanhudi terletak di kecamatan Tanjung Pura, Kabupaten Langkat, Provinsi Sumatera Utara. Kecamatan Tanjung Pura di Kabupaten Langkat merupakan salah satu kecamatan dengan tingkat kesejahteraan yang belum memadai. Sebahagian besar masyarakat bekerja sebagai petani dan nelayan, dan umumnya mereka belum dapat memenuhi biaya hidup yang memadai dan gagal dalam menguasai potensi produktif yang tersedia. Salah satu cara yang dapat dilakukan adalah diversifikasi pekerjaan dengan menstimulasi jiwa wirausaha generasi muda di Tanjung Pura, antara lain dengan memberikan keterampilan khusus yang nantinya bisa dimanfaatkan oleh mereka untuk membuka usaha sendiri. Salah satu cara yang akan dilakukan adalah dengan memberikan workshop pembuatan losion anti nyamuk. Hal ini mengingat kecamatan Tanjung Pura memiliki prevalensi yang tinggi terhadap penyakit malaria dan demam berdarah dengue (DBD), sehingga sangat tepat untuk mengajarkan para siswa SMA dalam pembuatan losion anti nyamuk agar dapat turut serta menurunkan angka kejadian penyakit tersebut. Oleh sebab itu,tujuan umum program pengabdian pada masyarakat ini adalah meningkatkan minat berwirausaha pada murid sekolah menengah atas, menurunkan angka pengangguran dan angka penyebaran penyakit malaria dan DBD di Kecamatan Tanjung Pura. Target utama dari program ini adalah sekelompok masyarakat yang memiliki latar pendidikan terakhir golongan menengah atau setara yang berada di Kecamatan Tanjung Pura. Secara khusus, program ini bertujuan untuk melatih siswasiswi setingkat SMA yang ada di SMAN 1 Tanjung Pura dan SMA Swasta Samanhudi dalam berwirausaha untuk memproduksi losion anti nyamuk yang berbahan dasar minyak sereh.
\end{abstract}

Kata kunci : Stimulasi Wirausaha, SMA N 1 Tanjung Pura, SMA Swasta Samanhudi, Losion, Herbal, Universitas Sumatera Utara

\section{PENDAHULUAN}

Tanjung Pura merupakan salah satu Kecamatan di Kabupaten Langkat yang berlokasi sekitar $60 \mathrm{~km}$ dari Kota Medan. Tanjung Pura Merupakan salah satu titik yang dilewati oleh Jalan Raya Lintas Sumatera menuju Provinsi Aceh. Lokasi Tanjung Pura terletak di antara dua sungai yaitu Sungai Sei Wampu yang ada di kota Stabat dan Sungai Batang Serangan, yaitu sungai yang berada ditengah kota Tanjung Pura. Aliran sungai ini melewatihampir di seluruh bagian wilayah Tanjung Pura dan bermuara di perairan selat Malaka (Fata, 2010).

Berdasarkan data statistik Kabupaten Langkat (2014) dalam rentang tiga tahun terakhir menunjukkan bahwa mayoritas penduduk Tanjung Pura, bekerja di sektor pertanian, kemudian disusul bidang perdagangan. Sektor pertanian dan perdagangan menjadi mata pencaharian utama masyarakat bila dilihat dari persentase orang yang bekerja, yaitu sekitar 81 persen dari total tenaga kerja yang bekerjadi berbagai sektor yang ada. Sedangkan untuk tingkat pengangguran yang ada di Kabupaten Langkat penyumbang terbanyak bila dilihat dari tingkat pendidikan yang diselesaikan adalah lulusan SMA/SMK/MA.

Pihak mitra maupun pengusul program optimis terhadap prospek usaha mandiri dalam pembuatan losion dari minyak sereh ini. Pertama, bila dilihat dari kondisi kesehatan masyarakat di daerah Tanjung Pura, malaria dan demam berdarah merupakan salah satu penyakit terbesar yang mewabah di daerah tersebut. Hal ini 
Yuandani. et al. Stimulasi Wirausaha Pada Murid Sekolah Menengah Atas di Tanjung Pura Langkat...

mendorong minat pengusul untuk membuat program yang bermanfaat bagi masyarakat untuk menurunkan tingkat wabah malaria dan demam berdarah di kawasan ini. Sedangkan mitra kedua adalah di SMA Swasta Samanhudi yang letak nya tidak jauh dari SMAN 1 Tanjung Pura. Pelajar disekolah ini juga tergolong masyarakat menengah dikarenakan mayoritas orang tua mereka bekerja di sektor pertanian dan perkebunan. Hal inilah yang mendorong minat pengusul untuk memberikan pelatihan cara produksi losion anti nyamuk pada pelajar di SMA ini agar minat wirausaha masyarakat meningkat dan dapat dimanfaatkan untuk menambah peasukan perekonomiannya melalui sektor industri rumah tangga.

Kedua, bila dilihat dari data statistik Kabupaten Langkat, tingkat pengangguran yang tinggi berada pada masyarakat dengan pendidikan terakhir setara SMA. Hal ini mendorong minat pengusul untuk memberikan pelatihan kepada pelajar SMA dalam berwirausaha, dan diharapkan setelah lulus SMA mereka dapat membuka lapangan kerja sehingga mampu menurunkan angka pengangguran di wilayahnya. Berdasarkan hasil survei yang dilakukan oleh pengusul, masyarakat di daerah Tanjung Pura belum ada yang bekerja dalam sektor industri. Hal inilah yang mendasari keyakinan pihak pengusul maupun mitra terhadap pelatihan berwirausaha ini.

Bila dilihat dari aspek sumber daya manusia, kedua mitra sebenarnya telah memiliki latar pendidikan yang cukup baik, dikarenakan sedang duduk di bangku sekolah tingkat menengah. Selain itu, banyak dari pelajar SMA di daerah ini yang setelah lulus SMA tidak melanjutkan ke bangku perkuliahan. Hal ini dapat meningkatkan angka pengangguran, dan menurunkan perekonomian masyarakat. Hal ini tentu saja menjadi peluang besar kepada pengusul untuk sedini mungkin memberikan pelatihan berwirausaha kepada pelajar SMA di kedua daerah ini, agar setelah lulus SMA mereka memiliki bakat dan keterampilan dalam berwirausaha. Sehingga bakat tersebut dapat mereka manfaatkan untuk meningkatkan taraf kehidupan mereka dikemudian hari.

Hasil survei wawancara dengan kedua mitra menunjukkan permasalahan utama yang menghambat mereka mengembangkan usaha dalam bidang industri adalah terkait minimnya pengetahuan mereka tentang cara berwirausaha. Untuk menghasilkan produk losion yang baik perlu ditunjang oleh peralatan yang baik dan modern dalam rangka efisiensi dan efektifitas proses produksi dan pengemasannya. Peralatan utama yang diperlukan untuk memproduksi losion antara lain : lumpang, stamfer, timbangan elektrik, alat-alat gelas, sudip, perkamen, spatel, kertas perkamen, batang pengaduk, dan kaca arloji. Permasalahan kedua terkait modal yang mereka punya sangat sedikit untuk melakukan berwirausaha, sehingga mereka tidak berani mengambil resiko jika terjadi kerugian. Keadaan ini terjadi mengingat tingkat kesejahteraan kedua mitra masih tergolong rendah, karena kedua mitra juga masih tergolong remaja, dan orang tua mereka mayoritas hanya bekerja dengan cara berkebun atau pun bertani.

Permasalahan ketiga berkaitan dengan tinggi nya penyebaran penyakit malaria dan demam berdarah, dan angka pengangguran di Kabupaten Langkat yang tinggi menyebabkan masyarakat tidak memahami bagaimana cara mengatasi penyakit yang terjangkit di wilayah mereka.

Berdasarkan permasalahan yang dihadapi, pihak mitra sangat mengharapkan adanya bantuan pelatihan dan pendampingan secara kontinyu sehingga mereka benar-benar dapat mengembangkan unit usaha produk losion minyak sereh ini.

Solusi yang ditawarkan terhadap masalah mitra adalah meningkatkan keterampilan murid SMA di Tanjung Pura dalam hal: (a) pembuatan losion anti nyamuk; (b)pembuatan kemasan yang menarik agar dapat dijual; (c) memasarkan produknya; (d) meningkatkan kemampuan manajerial untuk menjalankan usahanya.

\section{METODE PEMECAHAN MASALAH}

Kegiatan akan dilakukan menggunakan beberapa metode pendekatan meliputi penyuluhan, pelatihan, dan pendampingan, serta bantuan alat-alat produksi kepada masyarakat.

\section{a. Tahap I (Penyuluhan)}


Yuandani. et al. Stimulasi Wirausaha Pada Murid Sekolah Menengah Atas di Tanjung Pura Langkat...

Pada tahap awal kedua mitra akan diberikan pengetahuan/wawasan mengenai prospek usaha yang akan mereka kembangkan, termasuk bagaimana teknik produksi, pemasaran maupun manajemen usahanya. Penyuluhan akan dilaksanakan dengan metode ceramah dan diskusi. Kegiatan ini bertujuan untuk lebih meyakinkan dan memantapkan pengetahuan, wawasan serta semangat kedua mitra untuk memulai usaha baru.

\section{b. Tahap II (Pelatihan Teknik Produksi dan Pengemasan Produk)}

Pada tahap ini mitra akan dilatih untuk membuat produk losion dari minyak sereh. Selama pelatihan akan dilakukan kegiatan pembimbingan dan konsultasi sehingga kedua mitra benar-benar mampu dan terampil membuat produk yang berkualitas. Selanjutnya mitra diberikan pelatihan mengenai cara pengemasan produk yang menarik dan memiliki ciri khastersendiri.

\section{c. Tahap III (Pelatihan Teknik Promosi dan Pemasaran Produk)}

Pada tahap ini mitra akan dilatih dan dibimbing secara kontinyu mengenai caracara mempromosikan dan memasarkan produk yang dihasilkan. Kegiatan ini akan didampingi hingga kedua mitra berhasil memasarkan produknya yang dapat menjamin keberlangsungan perekonomiannya.

\section{d. Tahap IV (Penyuluhan Tentang Manajemen Usaha)}

Pada tahap ini mitra akan dibekali dengan kiat-kiat mengelola suatu bisnis/usaha. Kegiatan dilakukan melalui ceramah dan diskusi hingga pihak mitra benar-benar menguasai konsep-konsep pengelolaan usaha yang baik.

\section{e. Tahap V (Monitoring dan Pendampingan)}

Pihak pengusul kegiatan akan melakukan monitoring dan pendampingan secara berkala untuk memastikan kemampuan berwirausaha dari kedua mitra.

\section{HASIL PEMBAHASAN}

Kegiatan pengabdian kepada masyarakat ini diawali dengan pengajuan proposal pada awal Juli. Pihak mitra yaitu SMA Negeri 1 Tanjung Pura dan SMA Swasta Samanhudi Tanjung Pura sangat menyambut baik kegiatan pengabdian ini karena pihak SMA Negeri 1 Tanjung Pura dan SMA Swasta Samanhudi Tanjung Pura merasa bahwa topik yang diajukan oleh tim pengabdian sangat penting untuk dilaksanakan. Kepala sekolah SMA Negeri 1 Tanjung Pura dan SMA Swasta Samanhudi Tanjung Pura juga sangat mendukung kegiatan ini dengan dikeluarkannya surat persetujuan sebagai mitra didalam pengabdian kepada masyarakat. Surat persetujuan ini menjadi dasar pertimbangan pengajuan proposal dengan topik (judul) pengabdian kepada masyarakat "Stimulasi Wirausaha Pada Murid Sekolah Menengah Atas di Tanjung Pura Langkat Sumatera Utara Melalui Workshop Pembuatan Losion Anti Nyamuk Berbasis Herbal". Kegiatan pengabdian ini kemudian dilaksanakan satu kali yaitu pada hari Sabtu, 15 Oktober 2016.

\section{Proses Kegiatan}

Pada hari Sabtu, 15 Oktober 2016 dilaksanakan kegiatan pengabdian kepada masyarakat di SMA Negeri 1 Tanjung Pura. Kesepakatan waktu ini diadakan agar siswasiswi yang mengikuti program pelatihan ini dapat memiliki kemampuan dalam berwirausaha terutama dalam hal pembuatan losion anti nyamuk berbasis herbal. Mahasiswa juga dilibatkan dalam tim pengabdian kepada masyarakat ini, dengan demikian dapat memberikan kemampuan soft skill kepada mahasiswa. Kedatangan tim disambut oleh wakil kepala kepala sekolah SMA Negeri 1 Tanjung Pura. Kemudian dilakukan penyiapan ruangan yang akan digunakan untuk kegiatan pengabdian. 


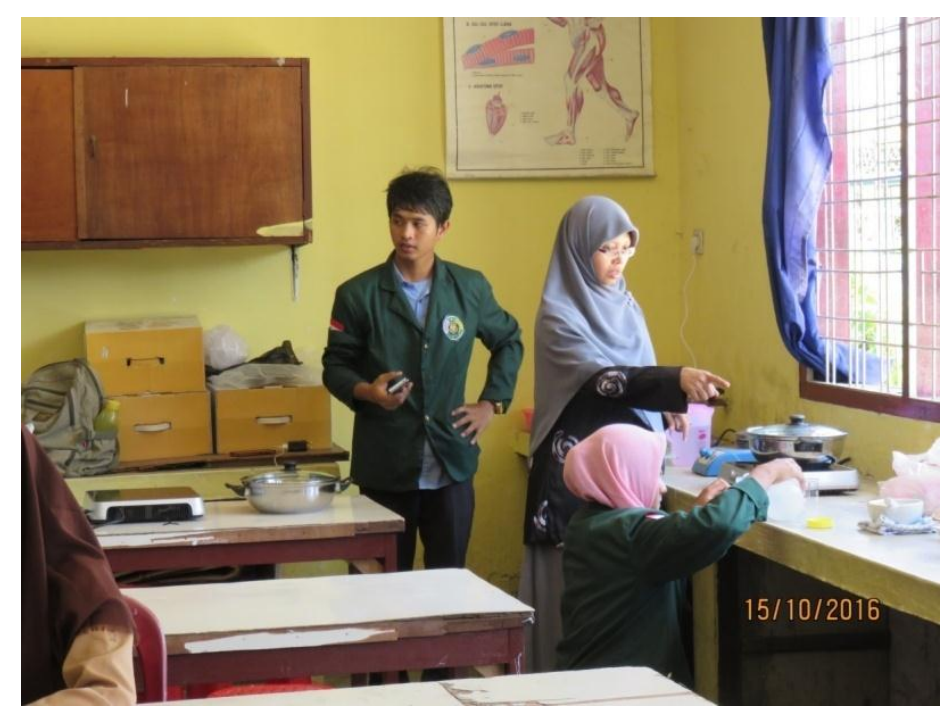

Gambar 1 : Persiapan bahan dan alat sebelum pelatihan

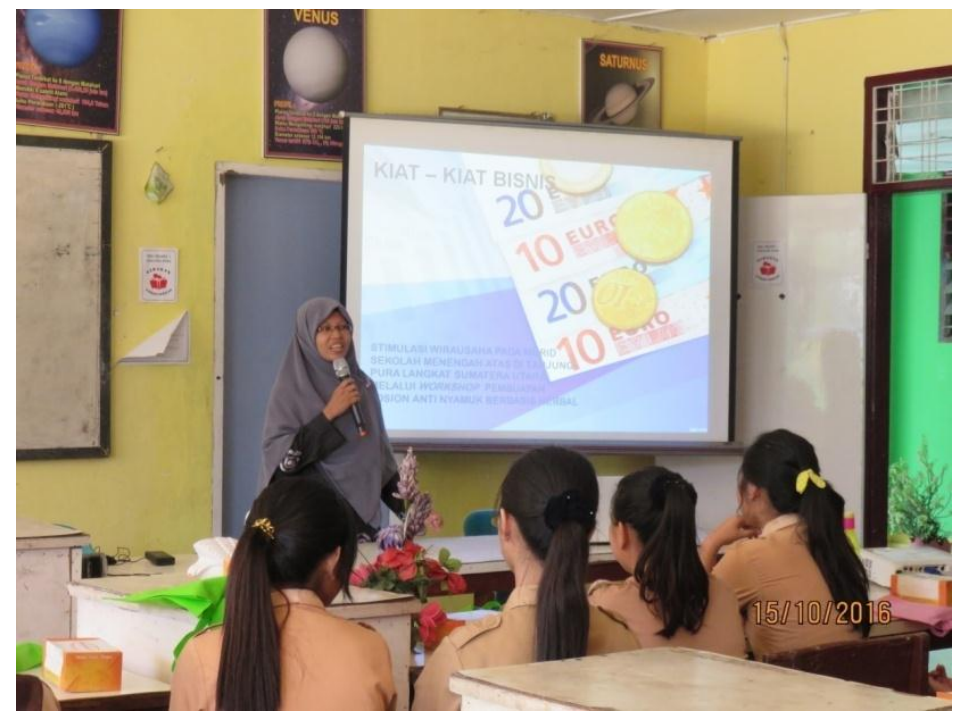

Gambar 2. Pemberian materi mengenai kiat-kiat bisnis oleh Ibu Yuandani, S.Farm., M.Si., Ph.D., Apt.

Kegiatan diawali dengan acara penyampaian kata-kata sambutan baik dari tim dan wakil kepala sekolah SMA Negeri 1 Tanjung Pura. Kata sambutan pertama sekali disampaikan oleh Ketua Tim Pengabdian, Ibu Marianne, S.Si., M.Si., Apt.; selanjutnya kata sambutan dari wakil kepala sekolah SMA Negeri 1 Tanjung Pura, yaitu bapak Ahmad Khairi, M.Pd. Kegiatan ini dibuka oleh anggota Tim pengabdi yaitu Ibu Yuandani, S.Farm., M.Si., Ph.D., Apt. untuk menjelaskan mengenai kiat-kiat dalam berwirausaha. 


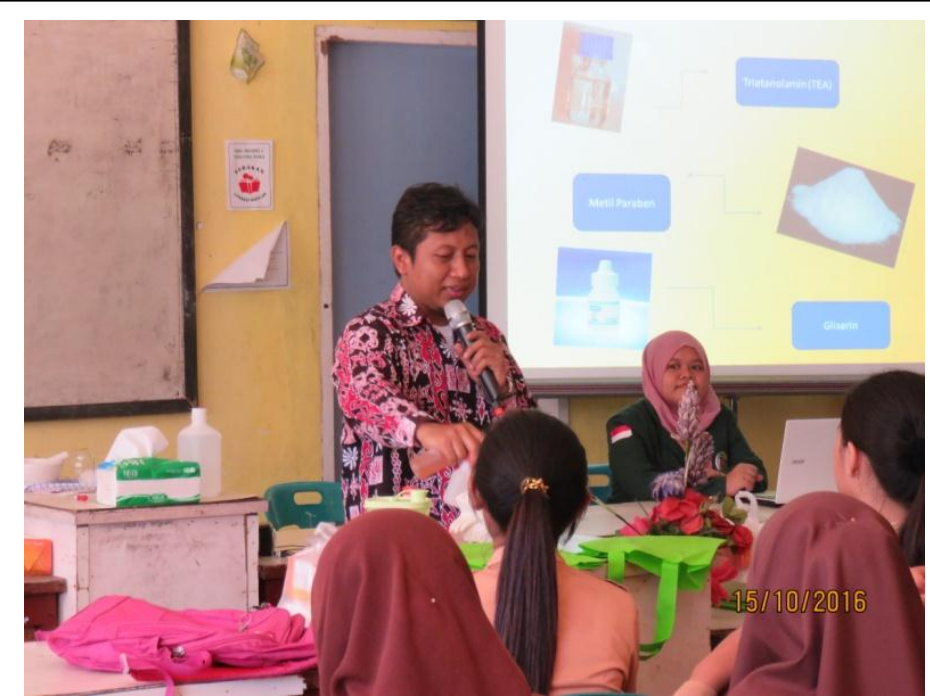

Gambar 3: Pemberian demo pembuatan losion oleh Bapak Popi Patilaya, S.Si., M.Sc., Apt.

Kegiatan ini dilanjutkan dengan demo presentase mengenai tahap-tahap pembuatan losion berbasis herbal yaitu oleh Bapak Popi Patilaya, S.Si., M.Sc., Apt. Bahan herbal yang digunakan dalam pembuatan losion ini terdiri dari 4 aroma yaitu, sereh, kenanga, lavender, jeruk. Sehingga siswa-siswi yang mengikuti pelatihan dapat memilih aroma losion yang mereka sukai.

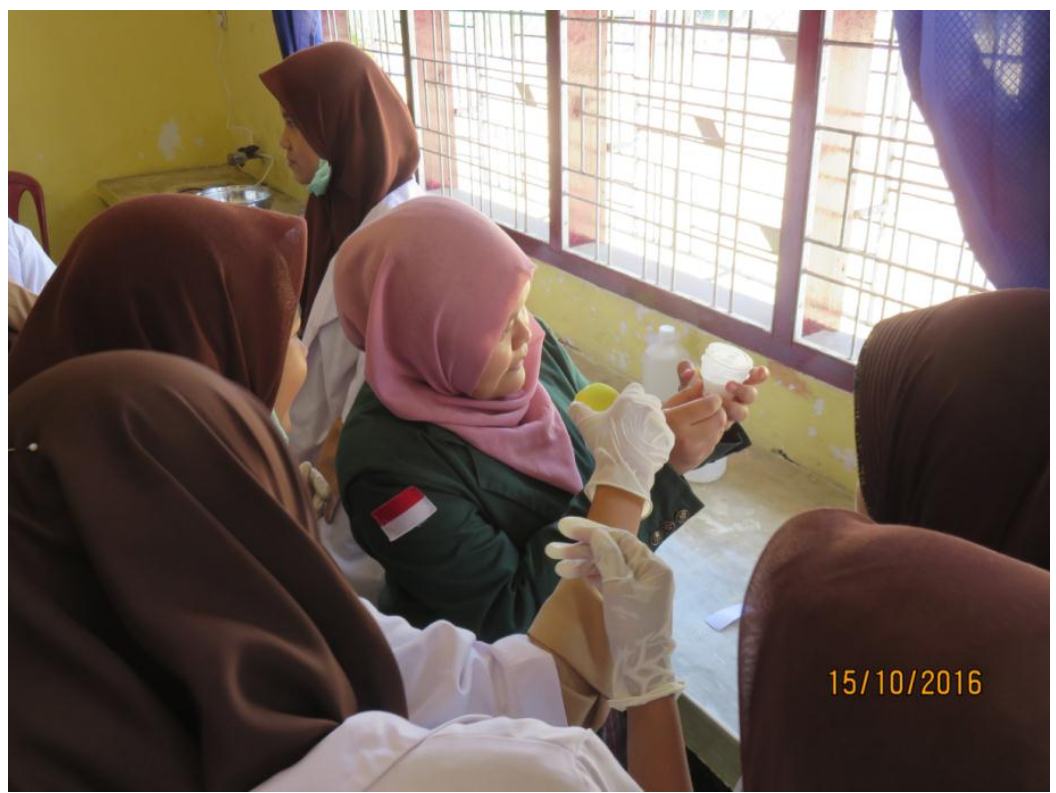

Gambar 4 : Suasana pelatihan stimulasi

Kegiatan ini dilakukan oleh tim dan dibantu oleh jajaran guru baik dari sekolah SMA Negeri 1 Tanjung Pura dan juga dari sekolah SMA Swasta Samanhudi Tanjung Pura.

Pelaksanaan kegiatan ini bertujuan untuk menstimulasi minat berwirausaha dari siswa-siswa SMA tingkat akhir yang akan segera meninggalkan bangku sekolah. Kegiatan ini juga sekalian untuk menyebarluaskan informasi mengenai dunia farmasi atau dunia obat-obatan kepada siswasiswi dan masyarakat. 


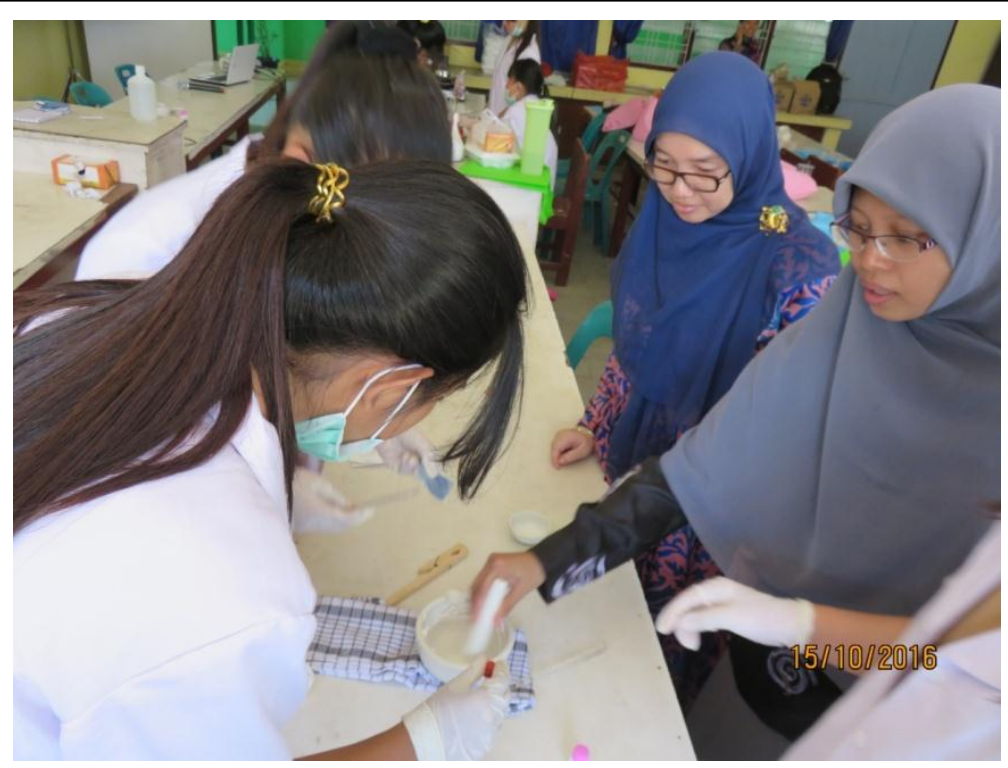

Gambar 4 : Proses peracikan losion

\section{KESIMPULAN DAN SARAN}

Kesimpulan

Berdasarkan uraian di atas maka dapat disimpulkan bahwa:

1) Pelaksanaan kegiatan pengabdian kepada masyarakat di SMA N 1 Tanjung Pura dan SMA Swasta Samanhudi, Kecamatan Tanjung Pura, Kabupaten Langkat, Langkat.

2) Kegiatan pengabdian yang dilaksanakan mampu memberikan pemahaman kepada peserta tentang potensi berwwirausaha dalam pembuatan losion berbasis herbal.

3) Produk losion berbasis herbal yang dilaksanakan oleh peserta memiliki aroma lavender, kenanga, citrus, dan sereh.

Saran

Perlu pendampingan lebih lanjut terhadap pihak mitra terutama dari aspek perijinan dan pemasaran, sehingga pihak mitra mampu menjalankan unit bisnis secara mandiri. Pelatihan-pelatihan secara berkelanjutan juga diperlukan untuk menyiapkan sumber daya manusia yang terampil sehingga mampu menghasilkan produk losion berbasis herbal yang bermutu sesuai dengan persyaratan yang berlaku.

\section{UCAPAN TERIMA KASIH}

Penulis menyampaikan terima kasih kepada Universitas Sumatera Utara yang telah mendanai kegiatan ini melalui surat tugas nomor : 570/UN5.2.3.2.1/PPM/2016. Penulis juga mengucakapkan terima kasih SMA N 1 Tanjung Pura dan SMA Swasta Samanhudi, Kabupaten Langkat atas dukungan dan kerjasama yang baik sehingga kegiatan workshop ini dapat terlaksana.

\section{DAFTAR PUSTAKA}

Balsam, M. S., \& Sagarin, E. (1972). Cosmetics. Science and technology. Second Edition. New York : John Wiley and Sons. 365-422.

Fata (2010). Selamat Datang ke Kota Kecilku ini dalam Wikipedia (https://id.wikipedia.org/wiki/Tanjung_Pura, Langkat). Diakses tanggal 19 Juli 2016. Pukul 18.30

Jacob, A., Pijoh, V. D., \&Wahongan, G. J. P. (2014). Ketahanan Hidup Dan Pertumbuhan Nyamuk Aedes spp Pada Berbagai Jenis Air Perindukan. Manado : Jurnal e-Biomedik 2(3).

Jas, A. (2007). Perihal Obat Dengan Berbagai Jenis dan Bentuk Sediannya. Jilid II. Medan : USU Press. 65 
Yuandani. et al. Stimulasi Wirausaha Pada Murid Sekolah Menengah Atas di Tanjung Pura Langkat... 